\title{
C-reactive protein levels: a prognostic marker for patients with head and neck cancer?
}

\author{
Astrid L Kruse*, Heinz T Luebbers, Klaus W Grätz
}

\begin{abstract}
Background: Recent advances in understanding complex tumor interactions have led to the discovery of an association between inflammation and cancer, in particular for colon and lung cancer, but only a very few have dealt with oral cancer. Therefore, the aim of the current study was to investigate the significance of preoperative C-reactive protein (CRP) levels as a parameter for development of lymph node metastases or recurrence.
\end{abstract}

Materials and methods: In 278 patients with oral cancer, preoperative CRP levels were compared with development of recurrence and metastasis.

Results: In 27 patients from the normal CRP group, and in 21 patients from the elevated CRP group, local recurrence was observed. Concerning lymph node metastases, 37 patients were in the normal group and 9 patients in the elevated CRP group. No significant correlation could be found between elevated CRP levels and metastasis $(p=0.468)$ or recurrence $(p=0.137)$.

Conclusion: Our findings do not appear to support a correlation between preoperative CRP levels and development of recurrence or metastases. In further studies, CRP levels in precancerous lesions and in Human Papilloma Virus (HPV) positive patients with oral squamous cell carcinoma (SCC) should be studied.

\section{Introduction}

In 1863, Rudolf Virchow postulated the induction hypothesis that cancer originated at site of chronic inflammation [1]. Chronic inflammation is associated with the risk of cancer. For instance, human immunodeficiency virus, viral hepatitis $B$, and human papilloma virus are well known for their association with an increased risk of cancer [1]. An argument for the hypothesis that inflammation is associated with cancer is also derived from the reduced risk for colorectal cancer that has been associated with long-term use of aspirin and other nonsteroidal anti-inflammatory drugs [2].

C-reactive protein (CRP) is an acute-phase protein and a marker for inflammation. The synthesis of CRP in the hepatocytes may be regulated by pro-inflammatory cytokines like interleukin-1, interleukin-6, and tumor-necrosis factor, which are also reported for different malignancies. Therefore, these pro-inflammatory cytokines are currently the subject of intense studies as

\footnotetext{
* Correspondence: astridkruse@gmx.ch

Department of Craniomaxillofacial and Oral Surgery, University Hospital Zurich, Zurich, Switzerland
}

influencing factors in various types of tumors. It is increasingly recognized that in addition to tumor stage, the disease progression depends on a complex interaction between the tumor and the host's inflammatory response.

Two hypotheses could be associated with increased CRP levels as a sign of chronic inflammation. First, the induction hypothesis: chronic inflammation results in excessive cell proliferation and activation of a cascade of cellular actions, leading to induction of irreversible DNA damage [1]. Second, the response hypothesis: the immune response of the host as a consequence of tumor growth itself could be the reason for the elevation in CRP levels [3]. However, it is still unclear whether CRP levels are elevated before the biological onset of cancer or if an elevated CRP level is also a risk factor for the development of cancer.

Findings from the studies, however, have been inconsistent. Some authors have observed an association between elevated serum CRP levels in some cancers, like colorectal [4-6] and lung [2]. On the other hand, some researchers doubt that CRP can be regarded as a prognostic marker [7]. However, raised CRP 
Table 1 Studies dealing with the association between oral SCC and preoperative CRP levels

\begin{tabular}{lll}
\hline Author & Number of patients & Results \\
\hline Gallo et al. [10] & 18 & Significance of CRP and IL-6 in regard to tumour stage \\
\hline Jablonska et al. [11] & 42 & CRP, IL-1b, IL-6, TNF-a serum levels related to clinical stage of disease \\
\hline Khandavilli et al. [12] & 60 & CRP level is associated with worse overall outcome \\
\hline
\end{tabular}

concentrations have been demonstrated to be an indicator of a poorer prognosis for squamous cell carcinoma (SCC) in patients with esophageal cancer [8,9], but concerning the cancer of the oral cavity only a very few studies have dealt with this topic so far (Table 1). All of these data are consistent with the hypothesis that CRP levels increase after onset of oral cancer.

Therefore, the aim of the current study was to investigate the significance of preoperative CRP levels as a parameter for development of lymph node metastases or recurrence.

\section{Materials and methods}

Chosen for evaluation were 278 patients (119 female, 159 male) with oral SCC that were treated between 1999 and 2008 at a single center (Department of Craniomaxillofacial and Oral Surgery, University Hospital Zurich). All serum CRP levels (obtained between one and 5 days prior to surgical treatment), recurrence rate, and lymph node metastases were taken into consideration. The minimum follow-up time was 12 months. Exclusion criteria were inadequate information and a follow-up time of less than 12 months.

The patients were divided into two groups according to the preoperative measure of $\mathrm{C}$-reactive protein concentration: those with CRP values in the normal range $(<=5.0 \mathrm{mg} / \mathrm{L})$, and those with elevated RP levels ( $>5.0 \mathrm{mg} / \mathrm{L}$ ) according to Khandavilli et al. [12] and Komai et al. [13].

For statistical analysis SPPS 18 (SPSS Inc, Chicago, IL) for the Mac was used. P value $<0.05$ was considered to be statistically significant. Kaplan-Meier analysis with log-rank testing was used for univariate analysis.

\section{Results}

Out of 278 patients with a mean CRP of $7.36 \mathrm{mg} / \mathrm{L}, 193$ (69.4\%) patients had a preoperative CRP level $<=5 \mathrm{mg} /$ $\mathrm{L} ; 85(30.6 \%)$ patients had a CRP level $>5 \mathrm{mg} / \mathrm{L}$; and the distribution was independent of age (Fig. 1).

Local recurrence was seen in 48 patients (17.3\%), with a mean time of 24.31 months (range: $7-84$ months); $2 \mathrm{~cd}$ tumors in 24 (8.6\%); and no recurrence in 206 (74.1\%). Cervical lymph node metastases were observed in 46 patients $(16.5 \%)$ after a mean time of 18.27 months (range: 4-71 months), distant metastases in 14 (5\%), and no metastases in 218 patients (78.5\%).

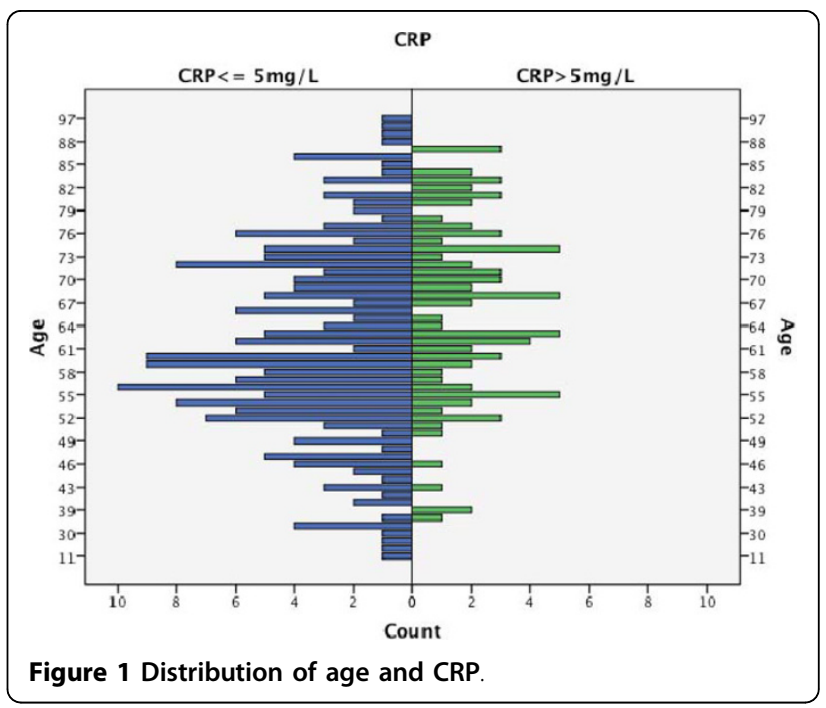

It was striking that although recurrence appeared earlier in the elevated CRP group (Fig. 2), no difference was found concerning the time of metastases (Fig. 3).

In 27 patients in the normal CRP group and in 21 patients belonging to the elevated CRP group, local recurrence was observed. Concerning lymph node metastases, 37 patients were in the normal group and 9 patients in the elevated CRP. No significant correlation was found neither for development of metastasis ( $\mathrm{p}=0.468$ ) (Fig. 4) nor for recurrence $(\mathrm{p}=0.137$ ) (Fig. 5).

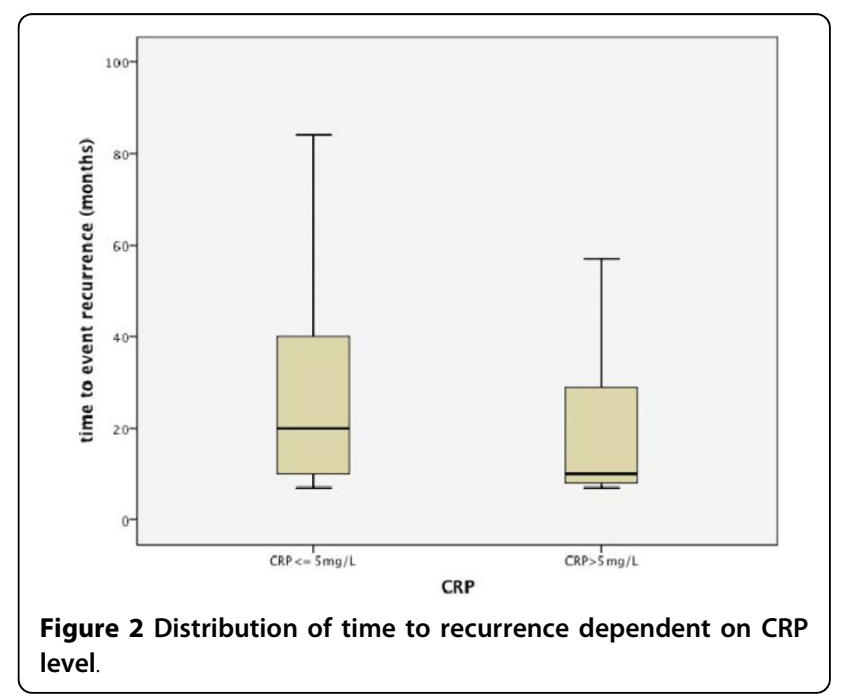




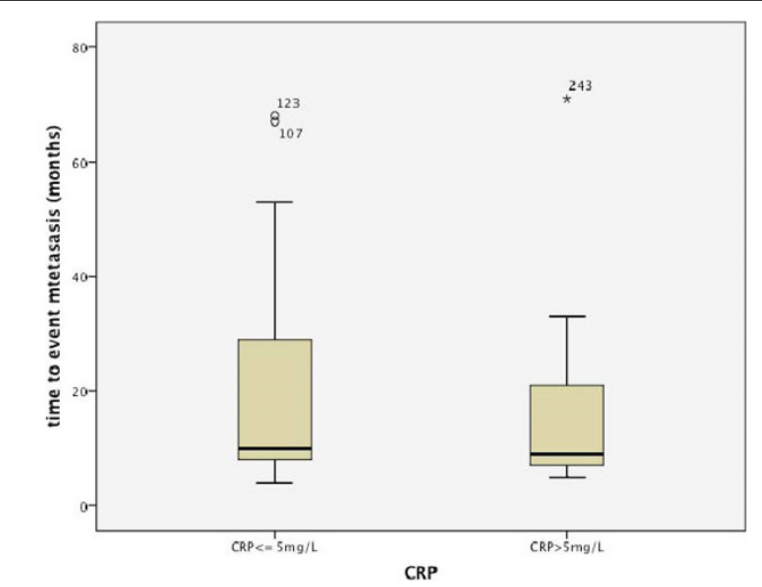

Figure 3 Distribution of time to metastases dependent on CRP level.
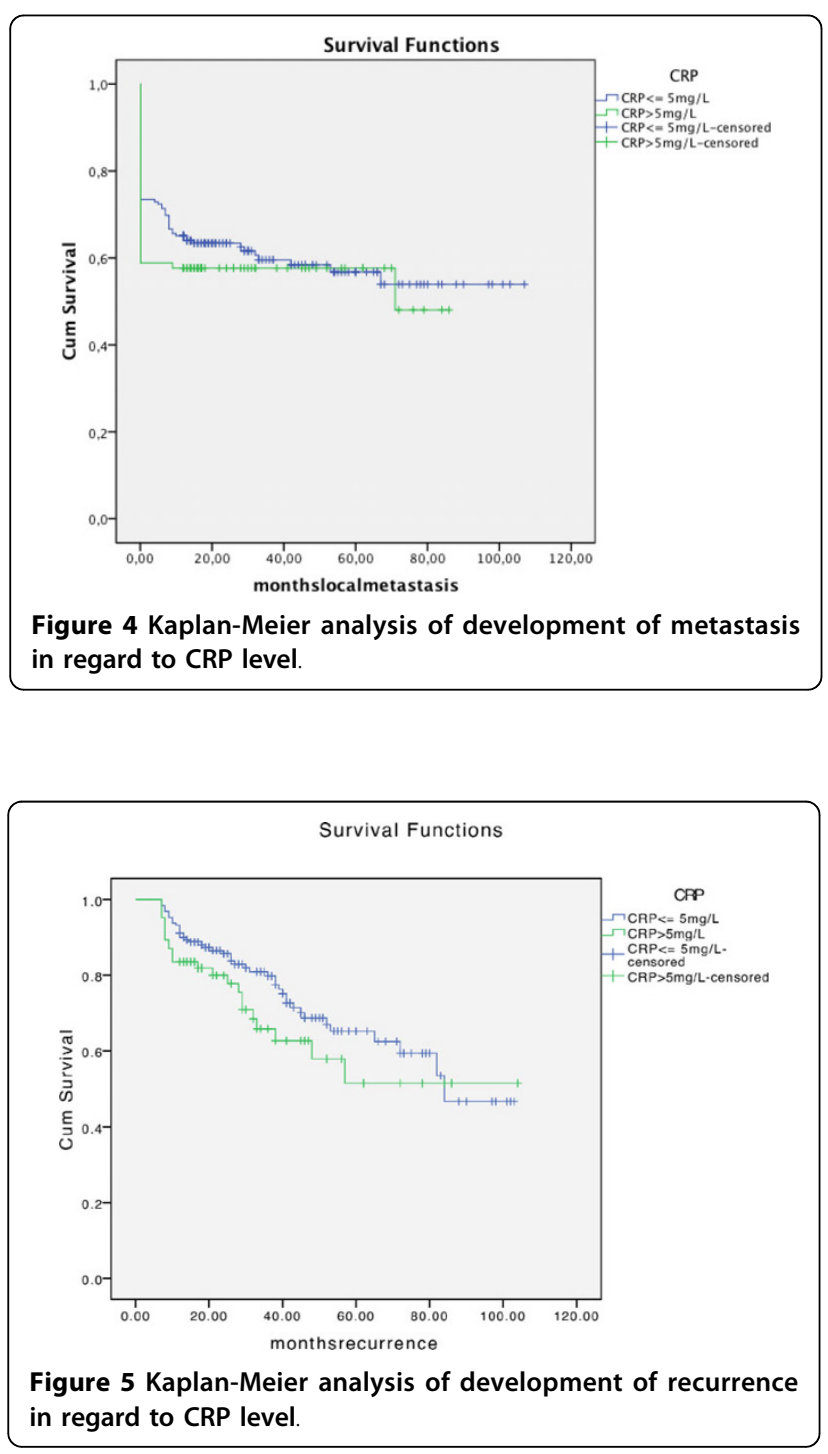

\section{Discussion}

In order to establish prognostic predictors for oral SCC, several studies have been performed. The purpose of our study was to find a simple and cost effective indicator for oral SCC. The mean follow-up time was 35.97 months (range: 12-107 months).

In this study, the mean value of serum CRP was 7.36 $\mathrm{mg} / \mathrm{L}$; the serum level was raised in 85 patients (30.6\%); the increase was mostly moderate (Fig. 1); and a high increase of more than $50 \mathrm{mg} / \mathrm{L}$, seen in infectious disease, was found in 6 patients. The proportion of lymph node metastasis in the group of elevated CRP levels was smaller than that in the patients without CRP elevation. But no significant association between raised CRP levels and development of recurrence or metastases could be seen. Therefore this study does not confirm the results from other studies (Table 1) and we also disagree with Zingg $U$ et al. [14] who suggested CRP-measurements in the re-staging process in patients who have undergone neoadjuvant treatment for esophageal cancer in order to help to select patients who are likely to benefit from surgery.

In the literature there seems to be inconsistency concerning the CRP levels: some authors have described CRP levels of more than $5 \mathrm{mg} / \mathrm{L}$ as raised $(13,14)$, while others have considered a more precise differentiation into three groups: low $(<1 \mathrm{mg} / \mathrm{L})$, average $(1.0-3.0 \mathrm{mg} /$ $\mathrm{L})$, and high $(>3.0 \mathrm{mg} / \mathrm{L})$. In the current study, a CRP level of more than $5 \mathrm{mg} / \mathrm{L}$ was considered as raised. But one has to keep in mind that CRP levels can be reduced with smoking cessation [15] and weight loss[16,17].

Patients with cancer of the oral cavity can be in poor nutritional condition. For esophageal cancer, a correlation has been shown between elevated serum CRP concentration and malnutrition with impaired immunity [9]. Furthermore, smoking and alcohol abuse can also lead to chronic inflammation in the oral mucosa. Therefore, it would be of interest to investigate CRP levels in precancerous lesions-e. g., erosive lichen. Ki et al. [18] reported a significant correlation between the presence of acute mucositis and CRP level in 40 patients during radiotherapy for primary laryngo-pharyngeal cancer.

A strength of the current study was the high number of patients. One limitation is that CRP was measured at one point in time. Therefore intraindividual variations were not considered. Furthermore, general diseases associated with possible higher inflammation markers like diabetes mellitus or Morbus Crohn were not taken into consideration due to lack of informations.

However, CRP is a nonspecific marker of inflammation, and additional studies of specific cytokines that regulate acute-phase response are necessary to elucidate the mechanisms by which inflammation influences the risk of cancer. 


\section{Conclusion}

In summary, our findings do not appear to support a positive association between preoperative CRP levels and oral SCC. Further studies should examine CRP levels in precancerous lesions and in HPV positive patients with oral SCC.

\section{Authors' contributions}

AK drafted the manuscript. TL participated in the design of the study. KG participated in its design and coordination. All authors read and approved the final manuscript.

\section{Competing interests}

The authors declare that they have no competing interests.

Received: 4 June 2010 Accepted: 2 August 2010

Published: 2 August 2010

\section{References}

1. Coussens LM, Werb Z: Inflammation and cancer. Nature 2002, 420:860-867.

2. Baron JA: Epidemiology of non-steroidal anti-inflammatory drugs and cancer. Prog Exp Tumor Res 2003, 37:1-24.

3. Siemes C, Visser LE, Coebergh JW, Splinter TA, Witteman JC, Uitterlinden AG, Hofman A, Pols HA, Stricker BH: C-reactive protein levels, variation in the C-reactive protein gene, and cancer risk: the Rotterdam Study. J Clin Oncol 2006, 24:5216-5222.

4. Erlinger TP, Muntner P, Helzlsouer KJ: WBC count and the risk of cancer mortality in a national sample of U.S. adults: results from the Second National Health and Nutrition Examination Survey mortality study. Cancer Epidemiol Biomarkers Prev 2004, 13:1052-1056.

5. Gunter MJ, Stolzenberg-Solomon R, Cross AJ, Leitzmann MF, Weinstein S, Wood RJ, Virtamo J, Taylor PR, Albanes D, Sinha R: A prospective study of serum C-reactive protein and colorectal cancer risk in men. Cancer Res 2006, 66:2483-2487.

6. Shiu YC, Lin JK, Huang CJ, Jiang JK, Wang LW, Huang HC, Yang SH: Is Creactive protein a prognostic factor of colorectal cancer? Dis Colon Rectum 2008, 51:443-449.

7. Zhang SM, Buring JE, Lee IM, Cook NR, Ridker PM: C-reactive protein levels are not associated with increased risk for colorectal cancer in women. Ann Intern Med 2005, 142:425-432.

8. Gockel I, Dirksen K, Messow CM, Junginger T: Significance of preoperative C-reactive protein as a parameter of the perioperative course and longterm prognosis in squamous cell carcinoma and adenocarcinoma of the oesophagus. World J Gastroenterol 2006, 12:3746-3750.

9. Nozoe T, Saeki H, Ohga T, Sugimachi K: Clinicopathological features of early esophageal squamous cell carcinoma with subsequent recurrence. Dis Esophagus 2002, 15:145-148.

10. Gallo O, Gori AM, Attanasio M, Martini F, Giusti B, Brunelli T, Gallina E: Interleukin-6 and acute-phase proteins in head and neck cancer. Eur Arch Otorhinolaryngol 1995, 252:159-162.

11. Jablonska E, Piotrowski L, Grabowska Z: Serum Levels of IL-1b, IL-6, TNF-a, sTNF-RI and CRP in Patients with Oral Cavity Cancer. Pathol Oncol Res 1997, 3:126-129.

12. Khandavilli SD, Ceallaigh PO, Lloyd CJ, Whitaker R: Serum C-reactive protein as a prognostic indicator in patients with oral squamous cell carcinoma. Oral Oncol 2009, 45:912-914.

13. Komai Y, Saito K, Sakai K, Morimoto S: Increased preoperative serum C-reactive protein level predicts a poor prognosis in patients with localized renal cell carcinoma. BJU Int 2007, 99:77-80.

14. Zingg U, Forberger J, Rajcic B, Langton C, Jamieson GG: Association of $\mathrm{C}$-reactive protein levels and long-term survival after neoadjuvant therapy and esophagectomy for esophageal cancer. J Gastrointest Surg 2010, 14:462-469.

15. Tracy RP, Lemaitre RN, Psaty BM, Ives DG, Evans RW, Cushman M, Meilahn EN, Kuller LH: Relationship of C-reactive protein to risk of cardiovascular disease in the elderly. Results from the Cardiovascular Health Study and the Rural Health Promotion Project. Arterioscler Thromb Vasc Biol 1997, 17:1121-1127.
16. SoRelle R: Sustain weight loss to downregulate inflammation. Circulation 2002, 105:e9075-9076.

17. Tchernof A, Nolan A, Sites CK, Ades PA, Poehlman ET: Weight loss reduces $\mathrm{C}$-reactive protein levels in obese postmenopausal women. Circulation 2002, 105:564-569.

18. Ki Y, Kim W, Nam J, Kim D, Park D: C-reactive protein levels and radiationinduced mucositis in patients with head-and-neck cancer. Int J Radiat Oncol Biol Phys 2009, 75:393-398.

doi:10.1186/1758-3284-2-21

Cite this article as: Kruse et al:: C-reactive protein levels: a prognostic marker for patients with head and neck cancer?. Head \& Neck Oncology 2010 2:21.

\section{Submit your next manuscript to BioMed Central and take full advantage of:}

- Convenient online submission

- Thorough peer review

- No space constraints or color figure charges

- Immediate publication on acceptance

- Inclusion in PubMed, CAS, Scopus and Google Scholar

- Research which is freely available for redistribution 